\title{
La traducción de los valores democráticos en la participación organizativa de la sociedad civil: un estudios de caso entre México e Italia
}

\section{Translating democratic values into organizational participation in non-profit organizations: a case study between Mexico and Italy}

\author{
IMKE HINDRICHS* \\ Cristina Girardo** \\ Daniela Converso***
}

\begin{abstract}
This article deals with the topic of democratic participation in non-profit organizations (NPO) from a psycho-organizational point of view. The first part discusses democracy as a horizon and an imperative for NPOS. Further, the references to transformational leadership and empowerment are posed as useful dimensions for analysis and improvement of organizational democratic cultures in NPOS. The second part presents the qualitative analysis by the method of template analysis as a compared reading of two organizational cultures in Mexico and Italy bound to the experiences of the Fair Trade Movement.
\end{abstract}

Keywords: non-profit organizations, democracy, professionalization, empowerment, organizational culture.

\section{Resumen}

En este artículo se aborda el tema de la participación democrática al interior de las organizaciones de la sociedad civil (osc) desde el punto de vista de la psicología organizacional. En la primera parte se estudia la democracia como horizonte e imperativo en las osc. Además, se plantea la referencia al liderazgo transformacional y al fortalecimiento como dimensiones útiles para el estudio y la mejora de culturas organizativas democráticas en las osc. En la segunda parte se presenta un ánalisis cualitativo con base en el método del template analysis, como lectura de dos culturas organizativas en México e Italia vinculadas con las experiencias del movimiento de comercio justo.

Palabras clave: organizaciones de la sociedad civil; democracia, profesionalización, fortalecimiento, cultura organizativa.

* Universidad Autónoma del Estado de Morelos, México. Correo-e: imke.hindrichs@uaem.mx

** El Colegio Mexiquense, A.C., México. Correo-e: cgirardo@cmq.edu.mx, c.girardo@hotmail.com.

*** Universidad de Turín, Italia. Correo-e: daniela.converso@unito.it. 


\section{Introducción ${ }^{1}$}

Desde hace tiempo, el tema de la democracia organizativa representa un campo de investigación interesante para los estudios organizacionales y para las ciencias sociales (Crouch y Heller, 1983). En este estudio focalizamos sobre todo las dimensiones psicosociales y psicodinámicas para contribuir a una comprensión multidisciplinaria del tema.

En particular, el trabajo de investigación que presentamos se desarrolla a partir del interés madurado en el tiempo por experiencias de investigación y de intervención en las formas de gobierno de las organizaciones de la sociedad civil (OSC), o non-profit (ONP), o más precisamente, de cómo en estas realidades los valores inspirados por el gobierno democrático se traducen en práctica. ${ }^{2}$ Hacemos referencia precisamente a la experiencia de investigación comparativa entre México e Italia llevada a cabo por el Programa Interdisciplinario de Estudios sobre el Tercer Sector (PIETS), de El Colegio Mexiquense, y el Departamento de Psicología (Área Psicología de las Organizaciones y del Trabajo), de la Universidad de los Estudios de Turín, en el marco del convenio bilateral firmado por ambas instituciones académicas.

En el intento de individualizar algunas organizaciones factibles para una comparación entre los dos países, nos hemos orientado a las experiencias del movimiento de comercio justo (CJ), por la relevancia que éstas han adquirido (con evidentes diferencias) en los últimos años en la sociedad civil de México e Italia (Perna, 1998; Cadena, 2005).

\section{La peculiaridad del gobierno democrático en el tercer sector: un proyecto ideal para personas concretas}

Tanto las Osc como las onp se ubican más allá de la esfera meramente pública y de aquélla únicamente privada y, según nuestro punto de vista, se asemejan mucho más entre sí de cuanto difieren. De acuerdo con los objetivos que aquí nos planteamos, citamos principalmente la definición de Lombardi et al:: "Consideramos el tercer sector como aquel conjunto

\footnotetext{
${ }^{1}$ Este trabajo de investigación se realizó con el apoyo de una beca otorgada por la Secretaría de Relaciones Exteriores del gobierno mexicano.

${ }^{2}$ La definición de las organizaciones a las cuales nos referimos en este trabajo, sobre todo con una perspectiva internacional entre México e Italia, no es unívoca y depende de los contextos históricos, culturales, políticos y sociales específicos de referencia, así como de las disciplinas que se ocupan de este sector (antropología, sociología, ciencias políticas, pedagogía, psicología). Mientras que en Italia se habla sobre todo de tercer sector u organizaciones non-profit (onP), en México prevalece el término organizaciones de la sociedad civil (osc). Para un análisis más profundo de las diferencias y similitudes definitivas entre América Latina, Europa continental y el mundo anglosajón, véanse Girardo (2003) y Mochi (2001). En adelante utilizaremos de forma indistinta las definiciones de tercer sector, sociedad civil y organizaciones non-profit.
} 
de organizaciones que tienen en común la producción de una utilidad difundida, es decir que corresponden contemporáneamente a las necesidades específicas de los usuarios, de los trabajadores y el ambiente que los rodea" (1999: 17).

En el centro de las onp están, pues, las personas y los lazos entre ellas (coasociados, beneficiarios, actores del territorio, etc.) y el proyecto ideal. Este proyecto a partir del cual estas organizaciones se crean está ligado con valores, principios, un ideal de cambio y de mejoría social que lleva a definir sus productos como relacionales (Converso, 2003) y a pensar "en el tercer sector como una clase de 'ciudadanía activa', participación en la vida de la sociedad, acción innovadora, como personas que se autoorganizan para responder a necesidades individuales y colectivas, y por ende, como en efecto muchas realidades del sector piensan de sí mismas" (Lombardi et al., 1999: 22). Las ONP sustentan los aspectos expresivos de sus miembros: en las ONP es posible satisfacer las necesidades de vida social y creatividad, explicar la propia personalidad, afirmarse, ser reconocido, tener una imagen favorable de uno mismo; tener responsabilidades o poder que no se consiguen en otros lugares (Converso, 2003).

Esta centralidad de la persona, de las relaciones y del proyecto ideal, junto con el factor participativo, se subraya de manera similar en un análisis de las osc en México:

A ellas conforme su filosofía y misión, corresponde insistir en la recuperación de la dimensión humana del desarrollo a fin de lograr que el centro de las políticas y programas sea el bienestar humano y no los indicadores macroeconómicos. Para esto, es necesaria la sistematización y la continuidad de procesos y métodos de trabajo favorecedores de la autogestión, las decisiones colectivas, la práctica democrática y el uso óptimo de los escasos recursos (AA.vv, 1997: 82).

El ideal de la democracia participativa está inscrito, de hecho, en la historia de muchas osc y se presenta así como un ingrediente fundamental para su especificidad, en contraste con los otros dos sectores, y para la calidad de vida de quien trabaja ahí, o bien, del trabajo desarrollado en sí mismo (Converso, 2003). ${ }^{3}$ La democracia y la participación para las osC "se convierten por un lado en principios imprescindibles, con la pena de caer en una contradicción interna insanable, y por el otro en instru-

\footnotetext{
${ }^{3}$ Generalmente, las onp se refieren y se vinculan por ley a formas jurídicas democráticas; es decir, constituyen tanto una expresión del proyecto ideal como una obligación ineludible. En Italia las leyes para las cooperativas sociales, las asociaciones de voluntariado y las organizaciones no lucrativas de utilidad social (onLus) las vinculan a un preciso sistema democrático de la forma organizacional: la mayoría de los trabajadores de una ONP son al mismo tiempo socios copropietarios de la organización, con derecho a voto igualitario (cada cabeza, un voto) y posibilidad de ser elegidos en los cargos de gobierno. En cambio, para las osc mexicanas, no en todas las formas organizacionales se encuentra esta coincidencia entre ser socios (detentar su propiedad) y ser trabajadores del sector (Girardo, 2007).
} 
mentos indispensables para el alcance de los propios objetivos" (Lombardi et al., 1999: 23). Esta tesis también la formula Acler en su análisis de las cooperativas sociales en Italia: "Los grupos que eligieron la formula cooperativa [...] se han vuelto conscientes de que hay coherencia entre el modelo organizacional elegido y los valores de referencia: servicio, solidaridad, función social, mutualidad, democracia y participación" (1995: 32). Pero tal conciencia, cuando se vuelve necesario traducir los principios democráticos en práctica organizativa, no exime de las dificultades que se experimentan cuando se intenta traducir los valores en comportamientos coherentes.

\subsection{Las paradojas ideal-típicas de la participación democratica}

Consideramos el hecho de que la democracia constituye tanto un horizonte como un imperativo del factor por el cual en las onp se pueden observar algunas tendencias a comportamientos ideal-típicos paradójicas, y también sugieren diferentes investigaciones y reflexiones llevadas a cabo en estas organizaciones.

Desde nuestra perspectiva de la psicología organizativa, vemos la organización en primer lugar como cultura: "un proceso dinámico de construcción, reconstrucción y destrucción de significados, proceso realizado a través de las acciones y decisiones individuales y colectivas definidas con base en un intercambio continuo, intersubjetivo entre los actores (Piccardo y Benozzo, 1996: 2).

Con esta referencia, vemos dos conceptos ligados con las relaciones humanas y con la política organizacional que hacen referencia a una compleja atribución de significados y que constituyen la base de las tendencias ideal-típicas: el conflicto y el poder.

La ambigüedad o la confusión que se puede producir entre los conceptos de democracia, consenso y conflicto puede conducir a veces a una especie de igualitarismo totalitario a partir de la convicción de que el consenso significa ausencia de conflicto (Acler, 1995). Sin embargo, en las organizaciones, el conflicto es intrínseco y en particular lo es en el tercer sector, compuesto por organizaciones complejas y difíciles para gobernarse, ya que deben coincidir una multiplicidad de intereses divergentes, casi siempre en conflicto potencial entre ellos. De esa manera se puede desarrollar una tensión entre una visión ideal-conflictiva y la confrontación con lo conflictivo como condición humana. De manera similar, seguir ciegamente el ideal de la democracia de base puede llevar a la completa negación de una dimensión de importancia central para cada relación humana: la dimensión del poder, de su ejecución y de las relaciones de poder que se instauran: "[La organización] es concebida y vivi- 
da como una comunidad de afectos en la cual las relaciones de poder no tienen más razón de existir. Sin embargo, esta vida democrática que quieren poner en práctica cotidianamente encuentra varios obstáculos desde el momento que los hombres no se adecuan a este esquema trivialmente roussiano" (Enriquez, 1996: 55, cursivas en el original).

A pesar de que con frecuencia es silenciada en todas las organizaciones (Piccardo, 1990, 1995, 1998; Quaglino, 2004), especialmente en el tercer sector es fácil que prevalezca una relación ambivalente con el concepto de poder, donde nadie debería ser diferente del otro (Converso y Piccardo, 2003; Montero, 2003; Santana, 2005). La dimensión del poder provoca relaciones asimétricas, en contraste con el valor de la igualdad. Si somos todos iguales, o bien (en una concepción más elaborada), si somos diferentes, pero tenemos los mismos derechos, ¿cómo puede alguien detentar más poder que los demás, más derechos (y también más deberes)? Del poder se ve fácilmente sólo la cara desagradable, la del dominio, de la coerción, de la sumisión, del chantaje y de la dicotomía patrón-sirviente. La cara amable del poder, entendido como potencialidad y creatividad, es decir, la cara de la solidaridad, de la oportunidad, del poder hacer (Piccardo, 1995), a menudo no se reconoce. Sería importante que también surgiera este lado del poder, que no toda la idea del poder quede negada, removida y sepultada. Es la cara del poder intrínseca, al ver las osc como lugar para expresar la propia personalidad y creatividad, donde se tiene al menos la posibilidad de...; es decir, el poder. Es la cara representada por la participación activa en el proceso democrático. En cambio, una concepción de democracia que niega implícitamente la oposición interna puede llevar a la dificultad de distinguir entre el sistema de decisión y el ejecutivo, que para Pagliarani se interpreta con base en un modelo psicosocioanalítico:

Otro obstáculo en la asunción del examen de realidad es la comprensión de la relación que debe subsistir entre sistema decisional y sistema ejecutivo. Pero no desde el punto de vista mental. Por el contrario, el concepto de por sí es bastante simple. Lo que es difícil, especialmente para quien profesa ideales democráticos, es liberarse de las defensas impropias contra la ansiedad emergente frente a la necesidad de organizarse para traducir en práctica las propias decisiones [...] Las instituciones [...] se paralizan frente al momento ejecutivo, recurriendo a varias defensas inconscientes (1973: 63, cursivas en el original).

Así, un primer comportamiento ideal-típico en las osc es la total parálisis organizacional: aparentemente para respetar el ideal democrático y de igualdad, no se vuelve operativo. A un nivel más profundo parece persistir la angustia de generar aquélla que en ocasiones Pagliarani (1985) llama la angustia de la belleza. Frente al rechazo y la ansiedad con respecto a organizar el sistema ejecutivo, y diferenciando funciones y cargos 
"para honrar el valor de la democracia participativa [se producen] discusiones sin fin también sobre cuestiones administrativas relativamente poco importantes" (Pearce, 1993: 148). Discusiones en las cuales también acaso se expresan unas ideas atractivas pero con las que no se llega a conclusión alguna (Kanter, 1972).

El estancamiento paralizante es un camino menos recurrente si una organización está dentro del mundo del trabajo. Por el contrario: las osc, sobre todo cuando los negocios van bien, cuando se empieza a lograr metas, cuando se han asentado en el territorio de pertenencia, pueden entrar en una crisis política; con frecuencia tratan de superarla eligiendo otro modelo organizacional ideal-típico, como la burocratización (Acler, 1995). La rígida definición de roles y tareas según racionalidad, la formulación de reglas y normas de comportamiento detalladas y la instalación de controles capilares, obsesivos, parecen alimentados por la ilusión de que por la vía de inventar mecanismos transparentes, poder y control, podrían quedar distribuidos igualitariamente en toda la organización. Cada uno sabe lo que debe y puede hacer, y da cuenta de eso; los roles, si acaso deben existir, se vuelven intercambiables. Tarde o temprano surgirán también todas las patologías de la burocracia (Barnett y Finnemore, 1999; Baum, 1987), como la desconfianza, la irresponsabilidad y la apatía. Las reglas se vuelven algo mágico que no se puede cambiar, dictan ley, poseen un poder inalcanzable; la relación, tan vital para las ONP, termina en intercambios de informes sobre el propio operador. Según Piccardo, la burocratización lleva a la politica del avestruz "que ignora los conflictos y evita la comparación, minimiza los problemas y apela al respeto de las normas burocráticas" (1990: 97). En el centro de atención no está la calidad del servicio otorgado, ni siquiera la calidad de vida que caracteriza a una organización auténticamente participativa, sino el respeto de las reglas y la ejecución de las tareas.

Si vemos las soluciones temporales de la parálisis, de la idealización de la visión y de la estructura burocrática siempre como tipos ideales en sentido weberiano, la burocratización representa la situación contraria a aquella de parálisis: el sistema ejecutivo funciona, en el sentido de que las tareas se ejecutan, pero el sistema decisional se vuelve despersonalizado y estéril. La participación es sólo una cuestión formal y la rigidez del mecanismo burocrático no admite cambios. Si antes el objetivo quedaba tan lejos que resultaba inalcanzable por ser demasiado idealizado, en la situación burocrática se pierde de vista por completo. 


\subsection{Los procesos de liderazgo y de fortalecimiento}

En la creación de una organización auténticamente democrática es necesario mantener el equilibrio entre tendencias paralizantes y burocratizantes en la "continua tensión entre expresividad e instrumentalidad, entre la dimensión fundacional y operativa" (Converso, 2003: 82). En ese intento parece fundamental no tanto la democracia efectiva sino la democracia percibida y vivida por los miembros de la organización. Desde una perspectiva psicológica, esta percepción se liga con las vivencias de relaciones de poder en las osc, que nos orientan sobre todo a dos conceptos: el liderazgo (entendido como proceso de relación entre líder y seguidores en un contexto organizacional) y de empowerment o fortalecimiento ${ }^{4}$ en su dimensión individual, relacional y organizativa.

Desde los estudios de Lewin (1972) existían ya varios intentos por definir el término liderazgo democrático (Gastil, 1994). Un concepto que "parece tener relevancia en particular para el sector del voluntariado5 donde las recompensas son más personales, sociales y basadas en el compromiso por ideales" (Avolio y Bass, 2004: 21), es lo de liderazgo transformacional elaborado por Bass a partir de 1985 con base en el concepto de liderazgo transaccional de Burns:

Los líderes transformacionales se vuelven una fuente de inspiración para los otros a través de su compromiso hacia quien trabaja con ellos, su perseverancia hacia una misión, su voluntad de asumir riesgos y su fuerte deseo de obtener éxitos. Los colaboradores confían en que sus líderes transformacionales superan cada obstáculo por su intenso trabajo y su voluntad de sacrificar su interés y sus éxitos personales (1978: 28).

Estamos de acuerdo con una concepción del liderazgo que se configura como fenómeno relacional ligado con los procesos de responsabilidad y de fortalecimiento más que con la posición de una persona individual. Sin embargo, en la mayoría de las definiciones de liderazgo surgen connotaciones normativas (el líder o los líderes y los seguidores deben portarse de cierta manera) y un presupuesto racional que ignora las vivencias inconscientes e irracionales que conforman la vida organizativa. Al legitimar a los líderes democráticos y transformacionales, se erige el tipo ideal de la

${ }^{4}$ De acuerdo con Montero, entre las varias posibilidades de traducción del concepto empowerment en lengua espańola, preferimos el término fortalecimiento (en lugar de los neologismos empoderamiento o apoderamiento): "Nos inclinamos por el término fortalecimiento por juzgar que refleja mejor la práctica que se quiere significar. Nuestro idioma no necesita del vocablo inglés, que [...] se refiere a los mismos aspectos contemplados por muchos profesionales del área en países hispanohablantes" (2003: 63).

${ }^{5}$ En las culturas anglosajonas, la expresión voluntary sector representa casi un sinónimo de non profit sector. 
autoridad racional (con su lado oscuro burocrático) de Weber (1995). Si a nivel formal, con el proceso electivo, el acto de legitimar a los líderes en el tercer sector se basa en aspectos racionales, en un aspecto simbólico, referente a la visión frecuentemente peyorativa del poder, el único poder inconscientemente aceptado en estas organizaciones muchas veces es el carismático. En lo manifestado esto se niega con frecuencia (Gastil, 1994), quizá porque al legitimar a la autoridad carismática se establecen dinámicas informales: la autoridad carismática se acepta por las dotes excepcionales (Weber, 1995) del líder, más que por su cargo oficial formalmente reconocido. Parece bastante recurrente que un líder carismático forme parte de un grupo fundacional de una osc, encarnación y portador de la visión organizacional (Pearce, 1993; Converso, 2003).

La psicodinámica del trabajo y de las organizaciones ha evidenciado los límites del liderazgo carismático. Por ejemplo, Kets (1989, 1994) explica los orígenes de la personalidad de un líder carismático con su posible desarrollo narcisista de niño. Sólo cuando alguien es guiado por un narcisismo de tipo contractivo, se puede volver un líder auténticamente carismático que sigue una visión y la sabe comunicar a sus colaboradores. En caso contrario, a un líder guiado por un narcisismo reactivo tal vez sí se le considere carismático, pero también es guiado por una necesidad continua de revancha y es celoso de su posición de poder, situación que hace difícil una disposición al fortalecimiento y a delegar el poder, basado en la confianza en el trabajo de los demás. Estos líderes quieren tener el control de todo cuanto pasa, a pesar de que se sacrifican -psicológica y físicamente- tal vez en nombre de la pretendida buena causa (Pearce, 1993; Pagliarani, 1996). Consideremos entonces el carisma también en su dimensión relacional y no nada más como característica del líder: son sobre todo los seguidores quienes pueden definir la identidad carismática de un líder (Gardner y Avolio, 1998). Esta dinámica relacional parece muy invadida por procesos de transferencia: Pauchant (1991) concluye que únicamente la relación entre un líder con una estructura de autoestima positiva y seguidores que también posean esa estructura puede llevar a un liderazgo verdaderamente carismático. Entonces, los líderes auténtica y constructivamente carismáticos escasean, mientras que los seguidores sin una autoestima suficientemente sólida corren el riesgo de perder la capacidad crítica frente al líder, colocándose en una situación de fuerte dependencia (Pauchant, 1991). Esta relación es psicológicamente ambigua, en especial en las osc: por un lado se legitima al líder porque es bueno, visionario y perspicaz; por otro, es el portador de las dimensiones peyorativas y negadas del poder. El líder que acepta una posición de poder otra vez se sacrifica en nombre de la misión. Así puede instaurarse un círculo vicioso y peligroso: al líder se le delegan todas las tareas innom- 
brables del poder, y él, por su cuenta, especialmente si es poco fortalecedor (no auténticamente carismático), arriesga la posibilidad de no delegar nada a nadie para no perder el control de la situación. Entonces se puede volver el chivo expiatorio (Converso, 2003): el padre (o la madre) carismático(a) y amado(a) se vuelve al mismo tiempo un jefe odiado.

Desde el punto de vista de los estudios sobre liderazgo, una perspectiva interesante y que puede servirnos para salir del atolladero entre un liderazgo ideal y los riesgos del liderazgo en las vivencias situacionales, se presenta por la crítica de las teorías y de los enfoques al liderazgo llevada a cabo desde un punto de vista epistemológico por Barker, quien intenta “distinguir el fenómeno del 'liderazgo' de las actividades, de las funciones y de las relaciones frecuentemente etiquetadas como liderazgo" (2001: 471). Desde un enfoque sistémico constructivista, este autor propone una definición alternativa:

El liderazgo es un proceso que no es específicamente una función de la persona encargada. [...] Es un proceso de adaptación y de evolución; es un proceso de intercambio dinámico y de valores. [...] El liderazgo puede definirse entonces como un proceso de cambio transformacional donde las éticas de los individuos se integran con la moral de una comunidad como medio del desarrollo social evolutivo (2001: 491, cursivas en el original).

En términos de proceso, esta definición de liderazgo lleva el discurso desde la dimensión funcional y relacional entre líder y seguidores hasta un ámbito más complejo de la cultura organizativa, donde el liderazgo "puede entenderse solamente como función del grupo" (Montero, 1998: 202); es decir, como proceso que involucra individuo y organización. Según nosotras, entonces se vuelve importante conjugar las teorías acerca del liderazgo con aquéllas sobre el fortalecimiento. De hecho, si en las osc el término liderazgo puede aludir al lado oscuro del poder, el concepto de fortalecimiento, en su significado inglés de acrecentar en poder (to empower: favorecer la adquisición de poder, rendir en grado de), llama a la idea del poder como dimensión favorable, algo que fortalece en lugar de someter; implica la posibilidad y la oportunidad de poder hacer más que de ser dominados. ${ }^{6}$ Se trata, pues, de un poder creativo que construye la realidad en vez de un poder destructivo y manipulador. Tener poder, ser fortalecido, en esta concepción significa no tanto detentar el poder como tener la potencialidad y la capacidad de actuar (Friedberg, 1993).

El concepto de fortalecimiento se origina con el término empowerment en Estados Unidos, en los estudios políticos y en el lenguaje de los mo-

\footnotetext{
${ }^{6}$ El verbo poder en las lenguas latinas (potere, pouvoir, poder...) indica la capacidad y la oportunidad, el ser en grado de hacer. Al mismo tiempo, el sustantivo alemán macht (poder) deriva de la misma raíz etimológica del verbo machen, o sea: hacer, crear, realizar.
} 
vimientos emancipadores y de lucha por los derechos civiles, de género y de las minorías acaecidos en la década de los sesenta. A partir de entonces ha sido adoptado, analizado y utilizando por diferentes disciplinas de las ciencias sociales y humanas, en particular la pedagogía y la psicología. Compartimos las críticas a las transformaciones del concepto en términos de excesivo individualismo y de pérdida de su significado colectivo y político (Burton y Kagan, 1996; Vázquez, 2004; Francescato y Tomai, 2005), pero seguimos convencidas de su utilidad heurística (Converso y Hindrichs, 2009). Vemos la posibilidad de recuperar su significado original precisamente en el encuentro con la corriente de la psicología social de la liberación latinoamericana (Martín, 1986; Burton y Kagan, 2005; Montero y Sonn, 2009), donde de hecho se encuentra el vínculo entre los conceptos y las prácticas de empowerment y fortalecimiento.

Una de las exponentes más conocidas de esta corriente es la ya citada psicóloga de comunidad venezolana Maritza Montero. En su análisis del concepto de fortalecimiento, afirma que este término es más antiguo que el de empowerment, pero también que "aunque se usaba el término castellano, no se le dio $[\ldots]$ un carácter central ni se elaboró una teoría a partir de él. Simplemente se incorporaban elementos fortalecedores en las estrategias de acción comunitaria y se lo advertía" (2003: 61). Por estas razones, la autora propone utilizar el término fortalecimiento y lo define como:

proceso mediante el cual los miembros de una comunidad (individuos interesados y grupos organizados) desarrollan conjuntamente capacidades y recursos para controlar su situación de vida, actuando de manera comprometida consciente y critica, para lograr la transformación de su entorno según sus necesidades y aspiraciones, transformándose al mismo tiempo a sí mismos (Montero, 2003: 72, cursivas en el original).

Así, en los estudios organizacionales entendemos el fortalecimiento como un proceso que involucra la organización como comunidad no sólo social, sino también política, como proceso al mismo tiempo psicológico y organizativo (Converso et al., 2010) que trasciende la relación dual líderseguidores y vincula, más bien, el liderazgo como proceso con la participación política y activa en la vida organizativa por personas subjetivadas.

Para las organizaciones del tercer sector, la promoción del fortalecimiento se puede considerar algo de importancia vital. En la mayoría de las osc se busca, con referencia a la utilidad social, la posibilidad de fortalecer también a terceros: los beneficiarios de las organizaciones socioasistenciales, los compañeros de trabajo desaventajados de las cooperativas sociales destinadas a la inserción laboral de personas débiles respecto del mercado de trabajo, la comunidad de pertenencia, poblaciones marginadas, etc. En palabras de Zimmermann, se trata de "organizaciones empowered [fortalecidas] que toman o influyen con éxito en decisiones po- 
líticas o que desarrollan alternativas reales en la oferta de servicios" (1999: 16 , cursivas en el original), organizaciones que quieren cambiar el mundo a favor de una mejor calidad de vida. Por eso es fundamental que las osc también sean organizaciones empowering -o sea, fortalecedoras-, que ofrezcan a sus propios miembros "instrumentos para obtener un control sobre su propia vida [y] la ocasión de desarrollar competencias" (Zimmermann, 1999: 15, cursivas en el original). No únicamente es cuestión de coherencia, sino parece ser crucial para el éxito a largo plazo de una organización fortalecedora. Es en este sentido que Converso y Piccardo desarrollan la hipótesis de doble fortalecimiento como necesidad en el tercer sector italiano que se ocupa de servicios a la persona:

el fortalecimiento individual de los sujetos disempowered, o a riesgo de disempowerment, puede realizarse solamente si se desarrolla paralelamente con la construcción de un funcionamiento organizacional que permite el fortalecimiento de los miembros comprometidos en sostener, acompañar, facilitar y crear las premisas organizacionales para el fortalecimiento de los sujetos a los cuales se dirige y con los cuales se coopera (2003: XI, cursivas en el original).

Así, el doble fortalecimiento se refiere a la promoción del bienestar recíproco. En esta perspectiva, el fortalecimiento de los beneficiarios "se da bajo la condición de que la organización con la cual los sujetos están en contacto, o sea sus vértices y todos los que operan en ella [...] se comprometen al mismo tiempo, y no menos significativamente, en el fortalecimiento individual y organizativo" (Converso y Piccardo, 2003: X-XI).

Nuestra hipótesis es precisamente que la posibilidad y la necesidad de procesos de doble fortalecimiento operan también en las osc que promueven el desarrollo en poblaciones marginadas, como se da generalmente en México, en particular cuando su crecimiento lleva a procesos de excesiva burocratización (Barnett y Finnemore, 1999), cuando ya no existe reciprocidad de comprensión y de respeto hacia las poblaciones locales a las cuales se dirigen los proyectos de desarrollo (Walker et al., 2007), o cuando la promoción de democracia en grupos marginados por la organización no corresponde a una democracia interna de la organización misma, como puede ocurrir en las organizaciones que se ocupan del comercio justo (CJ), de las que nos ocupamos en esta investigación (Rosi, 2003).

\section{La investigación}

Con esta investigación nos colocamos en el ámbito del paradigma constructivista que abarca a investigadores y participantes en el estudio como sujetos activos en un contexto social específico y de relación entre ellos en la coconstrucción de la realidad. En particular, nos ubicamos en la 
acepción del constructivismo sostenida por Guba y Lincoln (1994), según la cual "es idealista, donde ellos asumen que lo que es real es una construcción en las mentes de los individuos [...] Es también pluralista y relativista: hay construcciones múltiples y frecuentemente en conflicto entre ellos, y todas son (por lo menos potencialmente) significativas" (Schwandt, 1994: 128). En la tradición de la investigación-acción y con la intención de comprender las organizaciones como culturas, ${ }^{7}$ nos referimos más precisamente a los métodos de la etnografía organizativa y, en particular, al enfoque etnoclínico propuesto por Piccardo para "integrar un enfoque cultural al análisis y a la intervención organizativa, declinándolo con el saber psicosociológico [...] y psicosocioanalítico" (2002: 157; véase también Piccardo y Benozzo, 1996).

El estudio etnoclínico de una organización, según Piccardo y Benozzo, puede mostrarse "especialmente importante en algunas situaciones en las cuales se hipotetiza que el sistema de principios y valores que orienta el comportamiento de los actores sociales representa un obstáculo, o un recurso importante de reforzar, para la realización de determinados proyectos estratégicos u organizativos" (1996: 101). Como hemos visto, éste puede ser el caso en las organizaciones del tercer sector cuando el valor de la democracia obstaculiza la operatividad de la propia organización.

Con esta investigación nos proponemos comprender -en lugar de explicar- cómo los sujetos perciben y viven la participación democrática en dos culturas organizativas: una cooperativa social que se ocupa de la promoción del comercio justo (CJ) y de la comercialización de sus productos (cooperativa Mondo Nuevo) ubicada en Turín (Italia), y un centro de desarrollo comunitario (CDC) asentado en San Cristóbal de las Casas, Chiapas (México), que se ocupa de acompañar a grupos indígenas de productores, agricultores, y artesanas textiles en los procesos de organización, formación y comercialización de sus productos.

\subsection{La recopilación de datos}

Utilizamos instrumentos de recopilación de datos cualitativos típicos para la etnografía organizativa: observación participativa, entrevistas etnográficas y análisis de contenido de los textos escritos y de los artefactos organizacionales (Piccardo y Benozzo, 1996: 104). Mientras que la observación participante se desarrolló de manera libre (sin un formato predefinido) a

\footnotetext{
${ }^{7}$ En el caso de esta investigación, el concepto de cultura asume significados no sólo en términos de cultura organizativa, sino también en términos de culturas sociopolíticas, nacionales y étnicas diferentes y sobrepuestas.
} 


\title{
Cuadro 1 \\ Preguntas para las entrevistas semiestructuradas
}

\begin{abstract}
¿Cómo y cuándo entró en la organización? ¿Cómo se sintió acogido?
¿Cómo describiría su papel y sus tareas al interior de la organización?

Más allá de esas tareas, ¿de qué manera participa en la vida de la organización?

¿De qué manera sabe de las iniciativas de la organización?

¿Qué significa para usted formar parte de una organización social y no de otro

tipo de organización?

¿Podría describir cómo está estructurada la organización?

Según usted, ¿qué requisitos debe tener una persona para formar parte de esta organización?

¿Son estos los requisitos que se buscan, por ejemplo, cuando se decide invitar a alguien? ¿Cómo describiría el clima y las relaciones entre las personas en la organización?

Cuando hay problemas entre las personas o cuando usted se encuentra en alguna dificultad, ¿de qué manera trata de resolver estas situaciones?

¿De qué forma y quién toma las decisiones al interior de la organización y cómo se comunican?

a) ¿Podría imaginarse entrar algún día a formar parte del grupo directivo?

b) ¿Qué significa para usted formar parte del grupo directivo?

Confrontándola con otras organizaciones, ¿̨hay algo que hace especial a

esta organización?

¿Recuerda alguna anécdota que podría contarme y que según usted es representativa para la vida en la organización?

Resumiendo: ¿cuáles son, según usted, los puntos más fuertes y cuáles los más débiles de esta organización?

El futuro de la organización, ¿`cómo lo ve?

Para terminar, ¿me regalaría una metáfora que para usted podría representar a esta organización?
\end{abstract}

Fuente: Elaboración propia.

partir de la escritura de notas de campo,${ }^{8}$ las entrevistas fueron en su mayoría semiestructuradas y guiadas por un guión de preguntas predefinidas y acordadas con los sujetos participantes en la investigación (cuadro 1). ${ }^{9}$

La recopilación de datos en la cooperativa Mondo Nuovo en Italia se desarrolló en dos periodos (marzo de 2005-enero de 2006 y junio de 2006-junio de 2007) y esto nos permitió observar los cambios en los

\footnotetext{
${ }^{8}$ Estamos conscientes de que la atención a fenómenos y dinámicas particulares fue guiada por nuestra demanda cognoscitiva.

${ }^{9}$ Las preguntas se construyeron con base en dos criterios. Como marco utilizamos esquemas clásicos para la entrevista etnográfica: preguntas para romper el hielo que indagan la historia de entrada en la organización (Fontana y Frey, 1994: 370) y otras que intentan recoger indirectamente el sistema de valores de los entrevistados; por ejemplo, la demanda de atribuir un significado al trabajo en la organización específica y de confrontarla con otras, de narrar una anécdota particular o de regalarnos una metáfora que podría representar a la organización (Piccardo y Benozzo, 1996: 116-117). En este marco agregamos algunas preguntas referidas al proceso decisional y comunicativo, a la estructura organizacional, a los requisitos para la selección de personal, a la modalidad de resolver problemas, a la forma de participación en la vida organizativa y al significado atribuido al grupo de gobierno.
} 
procesos organizativos. Se involucraron todas las áreas operativas y todos los ámbitos de organización: fue posible participar en varios eventos organizativos (reuniones, asambleas, cotidianidad operacional, entre otros) y visitar casi todos los sitios físicos; tuvimos acceso a material escrito diverso, histórico y contemporáneo; de los más de 200 socios de la cooperativa, se entrevistó a 19 personas pertenecientes a todas las categorías:

- Diez de los 14 socios-trabajadores; dos de los mismos son socios fundadores y hay dos miembros del consejo de administración.

- Nueve socios voluntarios que forman parte de un grupo difícilmente cuantificable (incluso en la cooperativa participan como voluntarios personas que no son socias, mientras algunos socios se limitan a contribuir a la cooperativa con su cuota social) pertenecientes a los variados grupos de bodega, cinco de los mismos son fundadores y hay cuatro miembros del consejo de administración.

La recopilación de los datos en el Centro CDC en México se desarrolló en el periodo concentrado de marzo-mayo de 2006: una presencia en el campo casi cotidiana donde las notas de observación no se refieren sólo a la cultura organizativa, sino también a aquélla del contexto chiapaneco. Fue posible visitar varias veces los edificios del CDC en la periferia de San Cristóbal de las Casas, una tienda administrada por el Centro donde se venden los productos de cJ; dos de los diez grupos de artesanas indígenas que reciben el apoyo del equipo de Economía Comunitaria (EC). Las entrevistas (16 en total), con base en los acuerdos con los miembros de este equipo, se hicieron sólo con ocho de las nueve integrantes y no con miembros de otras áreas. Además se entrevistó a dos de las tres vendedoras de la tienda; y a seis artesanas: dos en una entrevista abierta en uno de ambos grupos, y cuatro en entrevistas semiestructuradas individuales.

El material escrito que fue puesto a nuestra disposición es finalmente bastante exiguo y en su mayoría de carácter publicitario (excepto la minuta de un día de capacitación en el segundo grupo de artesanas, en el cual fue posible participar). ${ }^{10}$

\subsection{Análisis de los datos}

Concentramos el análisis sobre todo en las transcripciones de las entrevistas conducidas y consideramos las notas de campo y el material escrito al mismo tiempo como fuentes para situar las narraciones en sus contex-

\footnotetext{
${ }^{10}$ Entendemos las diferencias consistentes entre ambas experiencias de levantamiento de datos. Sin embargo, nuestra investigación no está orientada a la comparación explicativa y de evaluación de las dos organizaciones, por ello no creemos que estas diferencias puedan demeritar los resultados del análisis.
} 
tos, como confrontaciones entre los valores públicamente declarados y compartidos (o menos) y efectivamente vividos, y como base de plausibilidad y credibilidad del análisis "sostenida sobre todo por la triangulación de los métodos" (Piccardo y Benozzo, 1996: 124).

Van Maanen define el proceso de análisis de datos cualitativos como proceso de traducción de "concepciones de primer nivel, aquellos, pues, propios del informador, sobre lo que sucede en el ambiente objeto del estudio [...] en concepciones de segundo nivel que tiene el investigador" (1979: 36-37). Con este objetivo nos colocamos en la tradición de la grounded theory -o muestreo teórico- (Glaser y Strauss, 1967) entendida como metodología (Strauss y Corbin, 1994) o "referencia operativa a través de la cual puede ser posible 'capturar' los conceptos de primer nivel relevantes para la producción de un nuevo orden de los mismos, o sea los conceptos de segundo nivel" (Piccardo y Benozzo, 1996: 126-127). Más precisamente, hacemos referencia a la propuesta metodológica de King (1998), el así llamado template analysis: "La esencia del enfoque es que el/la investigador(a) produce una lista de codificaciones ('template') ${ }^{11}$ que representa los temas identificados en los datos textuales. Algunas están definidas a priori, pero serán modificadas y adaptadas mientras que el/la investigador(a) está leyendo e interpretando el texto" (King, 1998: 118).

Al final del proceso analítico, construimos un conjunto de categorías predeterminadas (template inicial) con base en nuestro guión de entrevista y consideraciones teóricas organizadas según un modelo de dimensiones propuesto por el español Forcadell (2005a, b) como conclusión de su investigación en la cooperativa Mondragón ${ }^{12}$ presentada en el trabajo "Democracia, cooperación y éxito: implicaciones prácticas del caso de Mondragón": ${ }^{13}$ "Podemos extraer un conjunto de medidas para tratar de hacer realidad la democracia en las organizaciones en torno de las áreas siguientes [...]: cultura organizativa, stakeholders, estructura organizativa,

\footnotetext{
${ }^{11}$ La traducción literal del inglés template es andamio. Como transposición metafórica en español, el término no nos satisface plenamente: lo entendemos más bien como esqueleto, marco o telar en el cual construimos una estructura de categorías. Por esta razón, en adelante mantenemos la utilización del término original.

${ }^{12}$ La cooperativa Mondragón ha obtenido una discreta notoriedad en el ámbito de los estudios organizacionales gracias a la Investigación Acción Participativa empezada por Whyte y Whyte (1988) y desarrollada por Greenwood y Gonzales (Greenwood y Gonzales, inédito; Gonzales, 1991) en los años ochenta.

${ }^{13}$ Del trabajo de Forcadell tenemos a disposición tanto la versión española (2005a) como en inglés (2005b). La versión en inglés es más exhaustiva en la presentación del trabajo de investigación, pero como las conclusiones en las cuales nos basamos sobre todo son sustancialmente idénticas, por razones lingüísticas nuestras indicaciones bibliográficas aluden a la versión castellana.
} 
procesos de decisión, personas y el propio proceso de democratización" (Forcadell, 2005a: 61). ${ }^{14}$

Además, durante la lectura analítica del material textual surgieron nuevas categorías, mientras algunas categorías predeterminadas se demostraron innecesarias o requerían ajustes, hasta alcanzar un conjunto jerárquico de categorías de cinco niveles (template final). Lo presentamos en el cuadro 2, hacia su tercer nivel, mientras mostramos con más detalle el desarrollo del análisis en el Anexo metodológico.

Nuestro objetivo fue llegar, a partir de la lectura confrontada, a una mayor comprensión de dos realidades situadas en contextos disímbolos, pero que comparten el intento -más o menos explícito- de traducir los valores de la democracia participativa en una praxis organizativa, y por su pertenencia -más o menos fuerte-al mismo movimiento social internacional. La escritura de la narración etnográfica como nexo entre ambas historias representó un ejercicio interpretativo y dialéctico, donde las realidades observadas y escuchadas devinieron recíprocamente tesis y antítesis; donde los fenómenos y las dinámicas encontradas en una cultura organizativa no habrían sido visibles si la otra cultura no hubiera funcionado de fondo para la primera, y al revés. En seguida presentamos una selección resumida de este intento.

\subsection{Análisis de resultados}

Aquí no podemos entrar en el detalle del análisis de los datos a partir de las reflexiones sobre el contrato psicológico entre participantes e investigadoras, ni sobre el análisis crítico respecto de las áreas de la democracia organizativa propuestas por Forcadell (2005a). Para profundizar en ello remitimos a la tesis doctoral de Hindrichs (2008), al tiempo que presentamos un resumen de los resultados, eligiendo sólo algunas de las macrocategorías de análisis: las culturas organizativas, la participación y los procesos de liderazgo y de fortalecimiento; las políticas de los recursos humanos y los procesos democráticos progresivos. Presentamos así la narración etnográfica como escritura interpretativa con base en nuestras referencias teóricas (tendencias hacia parálisis o burocratización y procesos de liderazgo y fortalecimiento) a partir de los textos mexicanos e italianos reorganizados según nuestro template analítico.

\footnotetext{
${ }^{14}$ Las áreas indicadas por Forcadell nos parecen útiles no tanto respecto de la "implementación de un sistema democrático de dirección en una organización” (2005a: 61), sino en cuanto base de nuestro template de categorías analíticas.
} 


\section{Cuadro 2 Template final del análisis}

1. Cultura organizativa

1.1. Presencia de una cultura democrática

1.1.1. Valores democráticos/democracia como valor

1.1.2. Valores de $\mathrm{cJ} / \mathrm{CJ}$ como valor

1.1.3. Otros valores nuevos

1.2. Lo vivido en la organización

1.2.1. Motivación (de entrada y de quedarse)

1.2.2. Acogida

1.2.3. Clima

1.2.4. Participación informal

1.2.5. Anécdotas

1.2.6. Significado organización

1.3. Evaluación de la organización

1.3.1. Puntos de fortaleza/positivos/ ventajas

1.3.2. Puntos de debilidad/negativos/ desventajas

1.3.3. Percepción del futuro

1.3.4. Especificidad organización

1.4. Metáforas

2. Stakeholder

2.1. Democratización de propiedad y poder

2.1.1. Participación en propiedad

2.1.2. Participación en poder

2.2. Liderazgo compartido y relacional

2.2.1. Grupos de gobierno y grupos dirigentes

2.2.2. Fortalecimiento

2.3. Relación con stakeholder externos

2.3.1. Sistema de alianzas

2.3.2. Anclaje territorial/local

2.3.3. Trabajo en red/movimiento CJ

2.3.4. Alusión al zapatismo
3. Estructura organizativa

3.1. Estatuto con criterios democráticos

3.1.1. Descripción del organigrama

3.1.2. Sistema de reglas

3.2. Diseño de la estructura basado en la asociación

3.2.1. Constitución de grupos autogestionados

3.2.2. Relaciones y coordinación entre organismos internos

3.3. Funciones operativas y jerárquicas

3.3.1. Sistema de roles

3.3.2. Funciones y tareas percibidas

4. Establecer procesos democráticos

4.1. Proceso de decisión

4.2. Proceso comunicativo

4.3. Libertad información/transparencia

5. Personas

5.1. Educación y capacitación

5.1.1. Aprendizaje como valor

5.1.2. Capacitación para el interior

5.1.3. Capacitación para el exterior

5.2. Política de personal

5.2.1. Selección del personal

5.2.2. Formas de contratación

6. Procesos de democratización progresiva $y$ democrática

6.1. Autocrítica y dinamismo

6.2. Modalidad de resolver problemas

6.3. Conflictividad

Fuente: Elaboración propia. 


\subsubsection{Las culturas organizativas en los valores democráticos y del comercio justo}

Recordemos, según nuestra perspectiva, que las organizaciones no tienen, sino más bien son culturas (Piccardo y Benozzo, 1996). Así, analizamos algunos valores observados en ambas organizaciones y explicados por sus miembros.

En ambos casos, los valores democráticos parecen expresarse de manera reflexiva en sus aspectos favorables y ominosos: la igualdad de derechos y deberes (en particular los de responsabilidad por los resultados); tolerancia, aceptación y valoración de las diversidades; la libertad de pensamiento y de palabra (siempre respetando al otro); la cooperación (como expresión de mutualidad, solidaridad, colaboración y reciprocidad); la centralidad de la persona (como sujeto individual específico que hay que reconocer y en el cual invertir, más bien que como fuerza laboral intercambiable); el compartir de las misiones y visiones organizacionales. En la organización mexicana, estos valores conducen también a la expresión explícita, ello en la mayoría de los entrevistados, del valor de la participación democrática misma como práctica que hay que promover en los grupos de artesanas, y como una costumbre consciente tanto en el CDC como en algunos grupos de artesanas, de los cuales el personal del Centro admira su manera de tomar decisiones de manera participativa.

En la organización italiana, en cambio, la participación democrática se expresa como valor casi exclusivamente por parte de los miembros del consejo de administración, como si la democracia por los otros entrevistados fuera vivida en la práctica, pero no de manera consciente. Más bien, son los valores del $\mathrm{CJ}$ los que expresan con contundencia y de manera compartida todos los entrevistados de la cooperativa MN: representan conscientemente el único ámbito de trabajo, la misión, la visión y la razón social fundacional de la cooperativa como "experiencia [...] centrada precisa y claramente en el Comercio Justo", ${ }^{15} \mathrm{y}$ todos lo indican como parte de la motivación para afiliarse a la organización. Formar parte del movimiento de CJ significa para ellos una manera objetiva y pragmática de participar en la construcción de la utopía de un comercio internacional basado en los valores de dignidad y justicia. Para la organización chiapaneca, el CJ representa sólo uno, pero no el único ámbito de actividad. Sin embargo, los entrevistados comparten de manera más o menos consciente sus valores, dado que trabajan de forma directa con productores organizados y favorecen su camino hacia una mayor autosuficiencia por medios no "asistencialistas" sino tangibles. Es interesante que tanto una entrevistada

\footnotetext{
${ }^{15}$ Se trata de una cita directa de una entrevista. Para hacerlas reconocibles al lector, en adelante se indica este tipo de citas en letra cursiva y entre comillas.
} 
mexicana como una italiana utilicen la misma metáfora del "grano de arena" para expresar su contribución pequeña pero objetiva en la construcción de reglas de mercado diferentes y de una economía "al servicio de las personas".

Desde la perspectiva del doble fortalecimiento en el ámbito organizativo, percibimos las reflexiones respecto de la pregunta, sintetizada por nosotras como categoría de análisis, "¿CJ para quién?, no sólo productores" (Rosi, 2003). Para algunas entrevistadas del equipo del CDC, esta categoría se expresa como crítica a la paradoja de su organización en el ámbito institucional, el grupo de gobierno organizacional promueve el fortalecimiento de las comunidades indígenas, pero no el del personal dependiente del Centro, que sin embargo en Chiapas lo vive: "Si queremos como institución fortalecer los liderazgos en los grupos, entonces, ¿por qué no lo hacemos también en el interior?, ¿por qué no fortalecer a las personas que tenemos en el equipo?" En Italia las exigencias de coherencia se expresan con orgullo para el "CJ de las organizaciones" propio del "modelo mediterráneo" y diferenciado del " $C J$ de los productos", más propio de Europa septentrional (AGICES, 2005). Por lo que concierne a la cooperativa MN, desde su fundación la política de personal se basa en la incorporación de trabajadores remunerados, y no se confía sólo en fuerza laboral voluntaria (como a su vez lo hacen otras organizaciones de CJ italianas). Además, se subraya que se ha decidido aplicar para los contratos laborales las mejores condiciones posibles para los trabajadores.

\subsubsection{Participación y procesos de liderazgo y de fortalecimiento}

Desde un punto de vista formal, sólo en la organización italiana, en cuanto cooperativa social, se reconoce la participación en propiedad y poder, además de estar activamente incentivada por su consejo de administración en términos de responsabilización de los socios. En la institución mexicana, la propiedad y el poder de decisión recaen formalmente en manos del grupo de gobierno organizacional, con sede en la ciudad de México (a unos 900 kilómetros de Chiapas), mientras que el personal del CDC desempeña sólo una función ejecutiva y operacional (al contrario, a los grupos de artesanas se les exige compartir la propiedad y el poder). Frente a esta paradoja, en los últimos años parecen implantarse procesos de participación en el poder en cada equipo y en el centro mismo, procesos ya consolidados y parcialmente institucionalizados en una asamblea general y en muchas otras reuniones, tanto operativas como estratégicas, de las diferentes áreas del centro.

Las diferencias entre ambas organizaciones, en lo que se refiere a la participación en cuanto a propiedad y poder, se encuentran también en 
el análisis respecto de la categoría del liderazgo compartido y relacional. En la cooperativa MN, más allá de las funciones electivas de su consejo administrativo, que en un ejercicio de rotación parece favorecida de manera declarativa y efectiva en un equilibrio entre continuidad y recambio, se ha efectuado una distinción formal en el organigrama entre el mismo consejo administrativo y un grupo dirigente. Sin embargo, persiste una cierta confusión entre los dos grupos, personificada en el triple papel de presidente, coordinador general y de área, cubierto por una única persona y reflejada en la incertidumbre de varios entrevistados al describir el proceso de decisiones. Vemos ahí el riesgo de una parálisis organizacional (tendencia a la indecisión), como aquél de la burocratización (la idea de que mediante la subdivisión formal de los roles y tareas, se puede resolver la confusión). Después, en el proceso de diferenciación, casi todos los trabajadores (y un buen número de voluntarios) de la cooperativa cubren funciones de responsabilidad formal, y a muchos se le atribuye una autoridad legitimada en "un sistema que no se basa en un coordinador fuerte que sólo hace él, sino donde, por el contrario, se tiende a confiar proyectos enteros a una persona". Esta subdivisión (más que repartición) de las responsabilidades se expresa como especificidad de la organización, pero también como peso por quien se siente solo con sus responsabilidades y no puede integrarse con los otros responsables y coordinadores en un trabajo grupal. Al consejo de administración se le reconoce sobre todo el hecho de haber gestionado correctamente el crecimiento de la cooperativa y de haberla estructurado de la mejor manera, pero se le percibe también como distante de la base y de la cotidianidad organizativa. Estas vivencias, interpretables como alusiones a la negación de la dimensión del poder y como un delegamiento hacia arriba, las recibe el consejo de administración que reacciona con reuniones de asamblea destinadas precisamente a la clarificación de su papel. No obstante la negación de un "liderazgo fuerte" de una persona, no se puede ignorar la firmeza de autoridad reconocida al presidente/coordinador de la cooperativa, a quien se le atribuye un papel de "motor decisional": muchas de las decisiones las toma él personalmente, pero siempre después de haber escuchado y tomado en consideración las opiniones de los demás. Se le describe al mismo tiempo como paciente y entusiasta (hasta demasiado impulsivo), y se le reconoce una gran "capacidad de escuchar, de reflexionar" y para sostener el diálogo continuo con cada persona. Los trabajadores recurren a él para planificar y evaluar el trabajo; en momentos de dificultad o de conflicto -otros afirman que él mismo tiende a evitar los problemas- se esperan de él soluciones y comunicaciones. Estas tendencias podrían instaurar un círculo vicioso de delegar funciones, pero parecen todavía contenidas parcialmente por la capacitad reconocida en el presidente/ 
coordinador de involucrar y de responsabilizar a las personas, y de promover la aceptación de desafíos y de apuestas (cualidades propias del liderazgo transformacional; Avolio y Bass, 2004). Se pueden entrever mecanismos de proyección hacia la figura del presidente/coordinador de los puntos, ya sean fuertes o débiles de la organización.

En el CDC, en cambio, se observan mecanismos de idealización de una ex líder: la coordinadora general que terminó su mandato a finales de 2005. No sólo quienes colaboraron con ella la recuerdan, sino también aquellos que entraron después en el equipo, como si el mito se quedara en la historia del Centro. Se le reconocen grandes experiencias y competencias en el ámbito de las osc y se le describe como muy comprometida y portadora de visión, desde el punto de vista político. Su actividad en el CDC se recuerda sobre todo en dos planos: el involucramiento de las personas (al reconocer sus cualidades y competencias, con apoyos al crecimiento personal y de carrera) y por haber encabezado la "planificación estratégica", un proceso reflexivo e innovador que ha involucrado a todo el personal del Centro y los representantes de los grupos indígenas de artesanas y productores, $\mathrm{y}$ ha aportado a la redefinición de las metodologías de trabajo y al sistema de roles. A esta coordinadora general anterior también se le reconocen las características de una líder transformacional con una autoridad carismática legitimada por todos sus colaboradores. Al parecer, con ella comenzó lo que Avolio y Bass llaman "efecto cascada", situación por la cual "el líder ha transformado a sus propios colaboradores a la vez en líderes transformacionales" (2004: 30): a diferentes personas que cubren puestos de responsabilidad en el Centro se les atribuyen cualidades de liderazgo similares a las de aquella mujer.

El hecho de que finalmente ella no renovara su contrato se atribuye (por parte de los entrevistados del equipo) a la percepción de que no gustó al grupo de gobierno organizacional de la ciudad de México. Luego de su dimisión, entre el CDC y este grupo parece explicarse la relación conflictiva en un proceso que se puede definir como desafío de fuerzas y que ha llevado al nombramiento del nuevo coordinador general por el grupo de gobierno, saltando las costumbres de selección de personal, un proceso narrado y evaluado de manera muy detallada por varios entrevistados. El grupo de gobierno organizacional parece haber reafirmado su propia posición de poder, como para recordar el límite de la autodeterminación del Centro. De hecho, la investidura del nuevo coordinador general es percibida por la mayoría de los entrevistados del equipo como "imposición" de una "persona que conocen hace mucho tiempo y que lleva [su] línea". Lo describen como una persona "autoritaria" que no conoce la realidad chiapaneca y que tendrá dificultades para "aterrizar" en ella, esto es, insertarse en el contexto sociopolítico y cultural de la región. Sin 
embargo, según varios entrevistados, se afirmará en su puesto formal, dado que cuenta con el apoyo del grupo de gobierno organizacional. Parece, pues, surgir la figura del chivo expiatorio que para los entrevistados personifica el rostro oscuro del poder y que debe convivir con el lado iluminado del fortalecimiento idealizado en su predecesora. Estos procesos parecen esconder el riesgo de una parálisis organizacional no tanto por la confusión entre sistema decisional y ejecutivo en una concepción unitaria, sino por la contraposición perpetua entre los sistemas según un enfoque radical (Morgan, 2002: 261-264) que conduce a "comportamientos de competencia empujados, donde la rivalidad es muy fuerte y un actor obliga la sumisión del otro" (Piccardo, 1990).

En lo que concierne a los procesos de fortalecimiento, para los empleados del CDC parece representar uno de los valores más compartidos, y constituye la misión y visión del propio trabajo de los entrevistados del equipo. Como misión se expresa en el material escrito de la institución. Muchos de estos entrevistados perciben la metodología de fortalecimiento de apoyar a los grupos indígenas, conceptualizada en la "planificación estratégica", como una de las cosas que más les gusta de su trabajo y que consideran como factor de fortaleza del Centro. Sin embargo, a veces parece difícil aplicar esta metodología e involucrar a los grupos de artesanas; se revela como un proceso largo y fatigoso; varios entrevistados advierten un avance lento y en ello ven una gratificación que los fortalece a ellos mismos y les da razón para conservar la esperanza (en esta dinámica de retroalimentación positiva parece visible un proceso de doble fortalecimiento). Las dimensiones del fortalecimiento las mencionan muchos entrevistados del equipo, ya sea como valores que hay que fortalecer en los grupos apoyados, o como experiencias de incremento de autoeficacia tanto de los individuos como del grupo de trabajo. Este sentimiento de autoeficacia parece haberse desarrollado mediante procesos donde la toma de iniciativa ha sido correspondida por un involucramiento en los procesos operativos y de gestión, y por el reconocimiento del trabajo. Delegar hacia abajo por parte de varias coordinadoras, además parece que reforzó el sentido de independencia, y estimuló la asunción de responsabilidades individuales y colectivas en un grupo caracterizado por relaciones de confianza, desarrolladas también por vivencias de sustento no sólo en la resolución de cuestiones operativas, sino también en momentos personales difíciles.

En la organización italiana los procesos de fortalecimiento nos parecen menos evidentes. No significa que no existan, pero el concepto nunca deviene explícito. Es más bien reconocible en la misión de ser al servicio del proceso de autodeterminación y de autoorganización de los productores, y en la responsabilidad consecuente. Otros trabajadores afirman su 
sentido de orgullo y de gratificación por la percepción de sostener económicamente con su propio trabajo a otras personas. A diferencia de los miembros del equipo del CDC, los socios de la cooperativa MN tienen menos posibilidades de recibir un feedback directo respecto del éxito de sus acciones por las organizaciones de productores del cJ, es decir, los beneficiarios. Otros trabajadores denuncian así un sentido de desfortalecimiento acaecido por la falta de gratificaciones que vayan más allá de los derechos laborales formales en la administración del personal. En la cooperativa MN, muchos entrevistados expresan el sentido de iniciativa como requisito deseable para los trabajadores, y se refleja en varias historias de ingreso: casi nadie ha llegado por casualidad o porque buscara cualquier trabajo remunerado; eligieron la Cooperativa al encontrar en ella un espacio donde aplicar las propias competencias e inventar nuevas tareas. Los entrevistados describen además muchas iniciativas tomadas por individuos y por grupos de base para promover la Cooperativa y al cJ, de manera improvisada y creativa, o bien, institucionalizada. Involucrar a personas y grupos forma parte de la política organizativa de la "cooperativa abierta" y representa la motivación para incorporarse con que cuentan varios entrevistados. Se narran procesos de un involucramiento siempre mayor. La posibilidad de incluir y de tomar en cuenta a las personas como individuos capaces se le atribuye a personas específicas con liderazgo notable. Sin embargo, varios trabajadores perciben que el mayor involucramiento corresponde también a un incremento gradual de las responsabilidades delegadas en ellos, más subdivididas que compartidas en un trabajo grupal. Algunos sienten el respaldo de sus colaboradores del propio grupo de pertenencia para asumirlas, mientras que otros advierten un sentido de abandono. Así, la carga laboral creciente parece indicar el límite del "proceso de autoalimentación de la motivación": muchos advierten así la necesidad de respirar para no perder la motivación e involucrarse de nuevo después "con mayor disponibilidad, mayor tiempo y mayor lucidez". Estos dilemas no permanecen inexpresados: se reciben en el consejo de administración.

\subsubsection{Inversiones en recursos humanos: formación y selección del personal}

Darle a la gente la oportunidad de capacitarse y favorecer su aprendizaje significa promover su autoeficacia individual y de grupo, así como darles la oportunidad de participar auténticamente en los procesos democráticos (Heller, 2003). Así, la formación puede representar una estrategia de fortalecimiento organizativo.

Es de particular interés observar cómo todos los entrevistados de ambas organizaciones afirman de alguna manera que el aprendizaje de 
por sí constituye un valor. Para todos, estas "ganas de aprender" y de "profundizar" parecen correspondidas también por la percepción de que el trabajo mismo en los respectivos grupos y organizaciones representa un proceso de aprendizaje (y de enseńanza) desde el punto de vista profesional, de relaciones y personal.

Los miembros del equipo del CDC, aunque atribuyan a la política personal del Centro la voluntad de acompañar a sus propios dependientes en un proceso de crecimiento profesional y personal, no narran la capacitación formal recibida por el Centro mismo. En cambio, la formación interior es una parte de las políticas de la cooperativa MN y se la reconoce como elemento importante que ya existe y que hay que reforzar para afrontar los puntos débiles, tanto en los aspectos de motivación, de relaciones y comunicativos, como en aquellos de profesionalización y de conocimiento del comercio internacional. En la organización encontramos varias estrategias de formación interna más o menos institucionalizadas: los encuentros mensuales (destinados no sólo a los socios de la cooperativa sino abiertos a la población general); la posibilidad para los trabajadores de participar en cursos ofrecidos por el consorcio nacional de CJ (Стм-Altromercato) y por agencias de capacitación locales; la oportunidad de cumplir el servicio civil voluntario y otras prácticas profesionales en la Cooperativa. En cambio, la formación del CDC se destina como actividad principal de la organización a los grupos de artesanas y productores indígenas. En las entrevistas, las artesanas y los miembros del equipo narran muchas anécdotas sobre el proceso de capacitación. El equipo ofrece un amplio abanico de posibilidades formativas que se refieren en particular no sólo al mejoramiento de la labor artesanal misma, sino también a la alfabetización, a aspectos de organización, de relaciones y psicológicos, y a la apropiación de los procesos de comercialización. Además, los grupos de artesanas reciben capacitación del exterior, en especial, por parte del CDC, pero también promueven el aprendizaje en su propio núcleo. En el caso de uno de los grupos conocidos, se trata de un fenómeno narrado por las mismas artesanas y reconocido por los miembros del equipo, quienes atribuyen la capacidad de enseñar sobre todo a la representante del grupo.Otro aspecto de las políticas de recursos humanos es la selección del personal. En las osc, ésta representa un proceso bastante delicado que llama al valor de la igualdad, contrapuesto al de la diversidad: ¿todos pueden afiliarse o podemos elegir a quién recibir? (Converso y Piccardo, 2003).

Sobre ello, parecen relevantes las estrategias de selección que surgen de las entrevistas con los miembros de uno de los grupos de artesanas más conocidos. Cuando describen la aceptación de un nuevo miembro en el grupo, narran un proceso bastante preciso: se le explica a la persona que solicita entrar la metodología de trabajo entre compañeras; no se le exigen 
referencias formales ni capacidades técnicas o la pasión para el trabajo artesanal; la única regla parece ser la de adherirse a los principios del grupo y cumplir con las tareas encomendadas de manera igualitaria. Luego se analiza en el grupo (por consenso) si se admite a la nueva afiliada y parece decisivo que ésta no sea alguien que "busca problemas". Según las artesanas, esto parece ser una buena estrategia para evitar conflictos a futuro. Sin embargo, cuando éstos ocurren, se platica en el grupo y, en el caso de que una reunión no fuera factible, si una artesana no está de acuerdo, si no se adhiere al consenso, se recurre también a la solución extrema de expulsarla del grupo. De cierta forma, la metodología consensual y paritaria en el grupo parece servir entonces sólo si se excluyen las diferencias y las opiniones divergentes; cuando se llega a una igualdad suficiente para poder seguir la propia lucha por la independencia como indígenas y como mujeres.

En el CDC, los miembros del equipo describen la selección del personal a nivel abstracto como un proceso muy formal, planeado mediante un sistema de reglas que incluyen la construcción de un conjunto de requisitos solicitados en relación con el rol que se busca (perfiles laborales), la publicación de convocatorias y una serie de entrevistas efectuadas por el comité de personal que, junto con el coordinador del área interesado, tiene el poder para decidir la contratación. En cambio, en el ámbito de la experiencia personal, casi todos los miembros del equipo narran un proceso informal, muchas veces empezado por casualidad y/o por conocimientos, aunque muchos recuerdan luego las entrevistas que debían tener. Parecen individualizarse tendencias de burocratización contenidas por una gestión flexible que para los entrevistados no resulta contradictoria, sino más bien una integración entre las exigencias de tener reglas y el pragmatismo de saber disfrutar de la buena suerte.

En la cooperativa italiana a nivel formal, en el transcurso de los años se han desarrollado estrategias y requisitos en continuo cambio. Tras varias experiencias desfavorables, no se ha llegado todavía a un proceso definitivo, reconociendo que la selección de personal es un tema difícil. En cuanto a la experiencia personal, hay pocos entrevistados que entraron por selección directa, mientras que la mayoría se ha involucrado gradualmente a partir de diferentes procesos: entrar como voluntario y en seguida la posibilidad de una oportunidad laboral; experiencias anteriores en otras organizaciones de CJ locales o nacionales; por medio del servicio civil o de prácticas profesionales. Esos procesos reflejan un proceso de decisión en aparencia anárquico, pero a posteriori, según un significado preciso, llamado por Cohen et al. (1972) modelo de la papelera y muy típico de la cooperativa MN. Además parece surgir, contrario a la organización mexicana, una preocupación por una falta de burocraticidad, 
comprendida como formalización y estructuración de funciones y reglas de procedimiento (una empresa que no selecciona el personal no es una empresa "seria"), contrapuesta a experiencias de procesos exitosos de socialización gradual.

\subsubsection{La democratización progresiva}

Los miembros del equipo del CDC narran un proceso de democratización que viene del pasado y que entra en crisis justo cuando se daba nuestra presencia en el campo, la "planeación estratégica": aparece como un proceso de decisión que permitió la participación en el poder de todos los actores involucrados en el Centro, trabajadores y beneficiarios; ese proceso parece que favoreció el doble fortalecimiento, tanto organizativo como individual. Compartir esta historia, con los valores y la visión que allí se expusieron, al parecer fue algo tan importante que incluso quien no ha participado lo menciona, pero esta participación parece que desbordó una conciencia de necesidad respecto del trabajo del Centro, que ahora permite narrarla de manera reflexiva. A la coordinadora general anterior se le atribuye la iniciativa del proceso; su estilo de liderazgo parece haber favorecido el involucramiento de gran parte del personal del CDC que ahora representa a la oligarquía carismática, siempre más independiente y autónoma respecto del grupo de gobierno organizacional. La metodología participativa, experimentada en la planeación estratégica, parece haber tenido al final un efecto de contaminación: para la manera de tomar decisiones, descrita como muy participativa en el Centro y en la planeación de nuevos procesos de cambio. Quizás esta contaminación modifica la percepción (por parte de miembros más recientes del equipo) del CDC como un lugar donde "hay mucha apertura, iniciativas... para nuevas actividades, para cambiar, para renovar"; aunque en el momento de dejar el campo todo este proceso parecía quedar en duda por el conflicto siempre más tenso con el grupo de gobierno en la ciudad de México; sin embargo, dudamos que se refleje en percepciones del futuro que parecen revelar un locus de control tendencialmente exterior frente a cambios inmediatos, temidos y no controlables.

En los dos ańos de permanencia en el campo con la cooperativa MN, hemos participado como observadoras en procesos de reflexión y de innovación recursivos y complementarios, donde una fuerte autocrítica va acompañada de propuestas y medidas innovadoras, procesos que reflejan el movimiento (en el sentido propio de moverse y participar), así como el ser empresa (al aceptar desafíos y apuestas). Ser autocríticos y dinámicos, sabiendo innovarse y afrontar los cambios, es algo que expresan varios entrevistados como valor distintivo de toda la organización y, en particu- 
lar, del presidente/coordinador: en esto vemos la proyección en la figura de liderazgo como el efecto cascada de las características del o de los líderes fundacionales hacia nuevas generaciones y nuevas oligarquías. Sin embargo, algunos advierten que el incremento continuo de la carga laboral limita la posibilidad de "saberse reservar el tiempo para pensar y ya". Los procesos reflexivos e innovadores que escuchamos y observamos reflejan el sistema de valores vigente en la organización como cultura; narran de diferente forma el futuro o el pasado de la organización. Las expresiones de crítica al estado actual y la imaginación del futuro van acompañadas, en la mayoría de los entrevistados, por ideas y propuestas de mejorías que se presentan como procesos reflexivos, los mismos que auspician innovaciones y representan, según nosotras, un modelo de participación activa y consciente en el poder. De acuerdo con muchos entrevistados, surge así la exigencia de primero mejorar lo que ya existe antes de aventurarse en nuevas empresas, ello sin perder la identidad dinámica de la cooperativa. Muchas propuestas expresadas en las primeras entrevistas (noviembrediciembre de 2005) parecen haber sido recogidas y apropiadas, de manera más o menos consciente, por el consejo de administración que se ha comprometido a realizarlas, lo que refleja la capacidad de sus miembros para escuchar a la base social. Otras propuestas terminaron por formar parte de los objetivos declarados y construidos colectivamente en el nuevo documento político de la cooperativa (2007-2010). Al encontrar esos procesos de autocrítica y de dinamismo, tenemos la percepción de que "es una cosa muy fluida nuestra organización [...] demasiado fluida", lo que parece esconder el deseo de una mayor burocratización, pero también podría interpretarse como testigo de una realidad capaz de afrontar y de gestionar los cambios.

\section{Conclusiones}

La democracia organizativa representa un fenómeno muy complejo en el que se consideran todas las dimensiones del acto de organizar. Hemos tratado de comprenderlo desde la óptica de la psicología social y de las teorías psicodinámicas, conjugando esta perspectiva con la root metaphor que concibe a las organizaciones como culturas (Piccardo y Benozzo, 1996). Sin embargo, estamos convencidas de que no es posible estudiar la democracia organizativa sólo desde un punto de vista psicológico y cultural, sin antes tomar en consideración las formas de gobierno formalizadas y los aspectos estructurales y estratégicos; aquellos marcos y expresiones propios de la vida organizativa, así como el contexto cultural, social, político e histórico en el cual se da el intento de traducir los valores democráticos en una práctica organizativa. Si por un lado esta multiplicidad de perspectivas 
nos pareció enriquecedora y fecunda, por otro, la sensación de abismarnos en ella en el proceso de análisis tomó el barlovento más de una vez.

Nuestra comparación entre las dos culturas organizativas sólo representa un intento de comprensión de dos conocimientos situacionales (Kaneklin, 1993) a partir de la lectura dialéctica apoyada por el método del template analysis (King, 1998). Creemos que el resultado de este intento enriqueció recíprocamente el análisis de ambas realidades encontradas. Según Piccardo y Benozzo, "es irrealista pensar en interrogar a los miembros de una cultura olvidándose de la dificultad por los 'peces' de describir el agua en la cual nadan cotidianamente" (1996: 14). En nuestra investigación, ampliamos esta metáfora al sostener que no sólo ellos, sino nosotras también nadamos en un mar específico, aquél de la cultura italiana y europea, y que detenernos en la cultura mexicana nos permitió reconocer unas dinámicas que de otra manera habrían quedado ocultas.

Reconocemos sin embargo los límites de este intento. Junto a la complejidad del fenómeno, la narración etnográfica entrelazada de hecho obligó a abandonar varias entradas interpretativas que se abrieron de frente a nosotras en el proceso de análisis, que resguardaban de manera demasiado desequilibrada una de las dos culturas organizativas, o que habrían llevado a la integración de categorías analíticas ulteriores en la estructura de nuestro template, y a un alejamiento del tema central de la democracia organizativa. Sin embargo, el estudio de las dos organizaciones nos permite ver concretamente algunas de las dinámicas analizadas en la parte teórica y de intuir algunas estrategias para un gobierno organizacional exitoso. Para que una participación auténtica se pueda dar, es necesario invertir de manera paralela en el fortalecimiento psicológico y organizativo. Por otro lado, el fortalecimiento psicológico necesita el involucramiento colectivo: no se trata de un proceso sólo individual, sino concierne al ámbito de las relaciones en y entre grupos de trabajo (se basa en dinámicas de retroalimentación y de respaldo recíproco) y está ligado con las dinámicas de liderazgo entendido como proceso de relación en función del grupo. A partir de estas premisas, la participación misma representa un antídoto eficaz contra tendencias paralizantes o burocratizantes: participar en la definición de buenas prácticas, es decir, de reglas y metodologías de trabajo, significa adquirir conciencia de los propios procesos organizativos, aumentar el nivel de confianza en el hacer del otro y apropiarse de una manera de trabajo compartida más bien que sufrida.

En cuanto orientadas por la investigación-acción y por el enfoque etnoclínico, nos exigimos que este trabajo pueda contribuir a una comprensión mayor de esa crisis y a sustentar algunos procesos de cambio. Como mencionamos, en la cooperativa Mondo Nuovo pudimos observar procesos de concientización y de innovación respecto de las prácticas de 
participación democrática en la organización; nos gustaría pensar que nuestra investigación ha contribuido a estos procesos. Sin embargo, no es posible repetir algo semejante en otras osc. La no repetición de una etnografía organizativa está en primer lugar en su misma naturaleza única y de situación: no se trata sólo de una situación contextualizada en el espacio, sino también de una situación temporal e histórica de contextos cambiantes. La duración prolongada de la presente investigación constituye, en segundo lugar, otro límite desde el mismo punto de vista etnoclínico: a partir de la entrada en el campo en la cooperativa Mondo Nuovo, hasta el fin de la redacción del informe, han pasado ya más de tres años, durante los cuales ha habido cambios, tras los cuales una mirada en la profundidad histórica puede alentar en los miembros que organizan una concientización respecto de la propia historia y cultura "observada por un ojo externo" (en palabras textuales usadas por los consejeros de la cooperativa después de la aportación de los primeros datos); pero también puede poner sobre la mesa problemáticas ya superadas que, sin un proceso de elaboración, podrían abrir heridas del pasado, ya sanadas.

Ante estas consideraciones, surgidas poco a poco durante la investigación, desarrollamos la idea de construir un instrumento cuantitativo de recopilación de datos, siempre con el objetivo de medir no tanto la democracia efectiva, sino aquélla percibida por los miembros organizacionales. La utilidad de tal instrumento podría, según nosotras, representar el principio de otras investigaciones orientadas a la intervención, donde la reflexión colectiva sobre los datos podría llevar a encontrar estrategias de cambio. Finalmente, compartir los datos con miembros de diferentes organizaciones podrá ayudar en la sistematización de buenas prácticas llevadas a cabo para contrastar los riesgos tanto de parálisis como de burocratización en los procesos de participación democrática.

El cuestionario, formado por el Multifactor Leadership Questionnaire (MLQ: Avolio y Bass, 2004), el Organizational Description Questionnaire (ODQ: Bass y Avolio, 1992) y 67 reactivos vueltos a la individuación de los diferentes niveles de fortalecimiento vividos en la organización, constituye la base para la segunda fase de nuestro proyecto de investigación sobre democracia y participación en las osc. Actualmente estamos aplicando el cuestionario a socios de seis osc (cuatro mexicanas y tres italianas, entre ellas la cooperativa Mondo Nuovo), y hemos presentado los primeros resultados en diferentes conferencias nacionales e internacionales (Hindrichs et al., 2010a, b).

Finalmente, bajo el auspicio de aprendizaje de América Latina formulado por Burton y Kagan (2005), paralelamente a nuestra labor de investigación de campo hemos profundizado nuestra lectura sobre la psicología de la liberación desarrollada en América Latina a partir de los años ochen- 
ta, en particular al interior de las prácticas de la psicología social comunitaria (Martín, 1986; Montero y Sonn, 2009). Estamos convencidas de muchos puntos de contacto y de contaminación entre esta corriente y la psicología de las organizaciones europea desde un punto de vista tanto paradigmático como epistemológico y metodológico (Burton y Kagan, 2009; Ussher, 2006), y así esperamos poder seguir en este diálogo.

\section{Anexo metodológico: proceso de desarrollo del template analysis}

A diferencia de la utilización ortodoxa del muestro teórico como enfoque epistemológico de construcción de teoría (a partir exclusivamente de los datos empíricos básicos sin alguna definición a priori de las demandas cognoscitivas ni de las categorías de análisis), su utilización como metodología de análisis permite predeterminar tanto las preguntas a los participantes de la investigación (por ejemplo, el guión para las entrevistas semiestructuradas) como de las categorías de análisis, y esa posibilidad está explícita en la propuesta del template analysis. Sin embargo, en la aplicación de las codificaciones o de las categorías analíticas se conserva la del muestro teórico (la codificación abierta, axial y selectiva). King (1998: 119) enfatiza precisamente en la codificación axial o jerárquica; además explica las múltiples posibilidades de modificar (no prohibidas por los padres fundadores del muestro teórico) el template inicial en todo el proceso de codificación (la atribución de segmentos de texto a una categoría analítica), hasta llegar a un template final.

Por medio del software AtlasTi para el análisis cualitativo de los textos, aplicamos nuestro template inicial de categorías al material textual levantado en Italia y México. En este proceso surgían del texto nuevas categorías, otras las diversificamos o -al contrario- las aglutinamos, mientras que algunas no encontraron aplicación.

Vemos como ejemplo en el detalle el desarrollo de la segunda macroárea propuesta por Forcadell (2005a, b) -la de los stakholder- que representa un eje central para el análisis de los procesos psicodinámicos y psicosociales ligados a la participación democrática. El mismo Forcadell diversifica esta área en democratización de propiedad y poder (2.1), liderazgo compartido y relacional (2.2) y relación con los stakholder externos (2.3). La participación en la propiedad (2.1.1) era analizable tanto por los estatutos y otros documentos escritos de las organizaciones, como por declaraciones de los entrevistados. La participación en el poder (2.1.2) la investigamos con dos preguntas de nuestro guión (¿De qué manera participa en la vida organizativa a nivel formal? y ¿Podría imaginar algún día ser parte del grupo de gobierno organizacional?) y podíamos observar su presencia (o ausencia) durante las visitas a reuniones y asambleas. En la 
categoría liderazgo compartido y relacional (2.2) analizamos las notas de observación y los comentarios en las entrevistas que se refieren a grupos de gobierno y dirigentes (2.2.1) y a sus componentes: encontramos la evaluación y el significado de figuras líderes, formales e informales, que surgían del texto y las relaciones con y entre ellas. De acuerdo con nuestra formulación teórica, añadimos a esta categoría la de fortalecimiento (2.2.2) -proceso complementario al de liderazgo- que analizamos a partir de siete dimensiones (2.2.2.2; véase Converso et al., 2010a, b): autoeficacia (2.2.2.2.1), responsabilidad (2.2.2.2.2), delegamiento e independencia (2.2.2.2.3), iniciativa (2.2.2.2.4), involucramiento y reconocimiento (2.2.2.2.5), confianza (2.2.2.2.6) y sustento (2.2.2.2.7). Además, y sobre todo en las entrevistas mexicanas, surgía la referencia al fortalecimiento como valor en sí mismo y como misión organizacional, de manera que añadimos esta subcategoría en nuestro template (2.2.2.1). Por lo que concierne a las relaciones con los stakeholder externos (2.3), diversificamos esta categoría en sistema de alianzas (2.3.1), anclaje territorial/local (2.3.2) y trabajo en red/"movimiento" (2.3.3). En las entrevistas realizadas en Italia, esta última subcategoría se distinguía además respecto del movimiento del comercio justo a nivel local (2.3.3.1), nacional (2.3.3.2) e internacional (2.3.3.3). En cambio, de las entrevistas conducidas en México, surgían varios comentarios al movimiento zapatista que caracteriza la situación chiapaneca, razón por la cual añadimos la subcategoría alusión al zapatismo (2.3.3.4).

\section{Bibliografía}

AA.vv. (1997), Organizaciones no gubernamentales. Definición, presencia y perspectivas, Trasfondo, México.

Acler, Carla (1995), "Democrazia, partecipazione e gestione del conflitto nella cooperativa sociale”, Impresa Sociale, 19, Turín, pp. 32-43.

Agices (Associazione Assemblea Generale Italiana del Commercio Equo e Solidale) (2005), "Carta Italiana dei Criteri del Commercio Equo e Solidale”, <www.agices.org>, 14 de enero de 2006.

Avolio, Bruce J. y Bernard M. Bass (2004), Multifactor Leadership Questionnaire, Mind Garden, Redwood Citty, Cal.

Barker, Richard A. (2001), "The Nature of Leadership", Human Relations, 54 (4), Londres, pp. 469-494. 
Barnett, Michael N. y Martha Finnemore (1999), "The Politics, power, and pathologies of international organizations", International Organization, 4, Toronto, pp. 699-732.

Bass, Bernard M. (1985), Leadership and performance beyond expectations, Free Press, Nueva York.

Bass, Bernard M. y Bruce J. Avolio (1992), Organizational Description Questionnaire, Mind Garden, Redwood Citty, Cal.

Baum, Howell S. (1987), The invisible bureaucracy, Oxford University Press, Nueva York.

Burns, James MacGregor (1978), Leadership, Harper and Row, Nueva York.

Burton, Mark y Carolyn Kagan (1996), "Rethinking empowerment: shared action against powerlessness", en Ian Parker y Russel Spears (eds.), Psychology and Society. Radical Theory and Practice, Pluto Press, Londres, pp. 197-208.

Burton, Mark y Carolyn Kagan (2005), "Liberation Social Psychology: Learning from Latin America”, Journal of Community and Applied Social Psychology, 15, Glasgow, pp. 63-78.

Cadena-Barquín, Félix (ed.) (2005), De la economía popular a la economía de solidaridad. Itinerario de una búsqueda estratégica y metodológica para otro mundo posible, El Colegio de Tlaxcala, A.C., Tlaxcala.

Cohen, Michael, James Gardner March y Johan Olsen (1972), "Un modello di scelta organizzativa a "cestino dei rifiuti", en James Gardner March (ed.), Decisioni e organizzazioni, Il Mulino, Boloña, pp. 287-334.

Converso, Daniela (2003), "La specificità delle organizzazioni non profit", en Daniela Converso y Claudia Piccardo, Il profitto dell'empowerment. Formazione e sviluppo organizzativo nelle imprese non profit, Raffaello Cortina, Milán, pp. 113-159.

Converso, Daniela y Claudia Piccardo (2003), Il profitto dell'empowerment. Formazione e sviluppo organizzativo nelle imprese non profit, Raffaello Cortina, Milán. 
Converso, Daniela e Imke Hindrichs (2009), "La declinazione del potere in gioco nell'empowerment”, Animazione Sociale, 6-7, Turín, pp. 62-69.

Converso, Daniela, Imke Hindrichs y Claudia Piccardo (2010), “Empowerment individuale e organizzativo", en Piergiorgio Argentero, Claudio Giovanni Cortese y Claudia Piccardo (eds.), Manuale di Psicologia del Lavoro e delle Organizzazioni, vol. 3, Psicologia delle Risorse Umane, Raffaello Cortina, Milán, pp. 209-229.

Crouch, Colin y Frank Heller (eds.) (1983), International Yearbook of Organizational Democracy, Wiley and Sons, Chichester, Reino Unido.

Enriquez, Eugène (1996), “Oltre l'aziendalizzazione della vita lavorativa”, Animazione Sociale, 97, Turín, pp. 25-61.

Fontana, Andrea y James Frey (1994), "Interviewing: the art of science", en Norman Denzin e Yvonne Lincoln (eds.), Handbook of Qualitative Research, Sage, Thousand Oaks, Cal., pp. 361-376.

Forcadell-Martínez, Francisco Javier (2005a), “Democracia, cooperación y éxito: implicaciones prácticas del caso de Mondragón”, Universia Business Review, Actualidad Económica, segundo trimestre, Madrid, pp. 54-67.

Forcadell-Martínez, Francisco Javier (2005b), “Democracy, cooperation and business success: the case of Mondragón Corporación Cooperativa”, Journal of Business Ethics, 56, Manitoba, pp. 255-274.

Francescato, Donata y Manuela Tomai (2005), Psicologia di comunità e mondi del lavoro, Carocci, Roma.

Friedberg, Erhard (1993), Il potere e la regola, Etas Libri, Milán.

Gardner, William y Bruce Avolio (1998), "La relazione carismatica", en Gian Piero Quaglino, Leadership. Nuovi profili di leader per nuovi scenari organizzativi, Raffaello Cortina, Milán, pp. 323-368.

Gastil, John (1994), "A definition and illustration of democratic leadership”, Human Relations, 47 (8), Londres, pp. 953-975. 
Girardo-Pierdominici, María Cristina (2003), “La formación para el trabajo de los jóvenes (desafíos y estrategias) desde las organizaciones de la sociedad civil", tesis doctoral, Universidad Nacional Autónoma de México, México.

Girardo-Pierdominici, María Cristina (ed.) (2007), La profesionalización de las OSC en México: actores y estrategias, El Colegio Mexiquense, A.C., Zinacantepec.

Glaser, Barney y Leonard Strauss Anselm (1967), The Discovery of Grounded Theory: Strategies for Qualitative Research, Aldine, Chicago.

Gonzales, José Luis (1991), "Participatory action research: a view from Fagor", en William Foote Whyte (ed.), Participatory action research, Sage, Newsbury Park, pp. 77-84.

Greenwood, Davyd James y José Luis Gonzales (1991), “Organizational Cultures in Mondragón: A Participatory Action Research Study of Change in the Fagor Cooperative Group", inédito.

Guba, Egon e Yvonne S. Lincoln (1994), "Competitive paradigms in qualitative research", en Norman Denzin e Yvonne Lincoln (eds.), Handbook of Qualitative Research, Sage, Thousand Oaks, Cal., pp. 105-117.

Heller, Frank (2003), "Participation and power: a critical assesment", Applied Psychology, 52 (1), Hoboken, Nueva Jersey, pp. 144-163.

Hindrichs, Imke (2008), “Tradurre il valore democratico in prassi organizzativa: il commercio equo e solidale tra Messico e Italia”, tesis doctoral, Università degli Studi, Turín.

Hindrichs, Imke, Daniela Converso y María Cristina Girardo Pierdominici (2010a), "The Paradox of Democratic Participation in NPO: Tools for Action-Research that Sustain Double Empowerment", memorias de la Ninth International Conference of the International Society for Third Sector Research (ISTR), Estambul, 7-10 de julio de 2010 (ponencia arbitrada).

Hindrichs, Imke, Daniela Converso y María Cristina Girardo Pierdominici (2010b), "Democracia organizacional y fortalecimiento en las organizaciones de sociedad civil (OSC). Diferencias y similitu- 


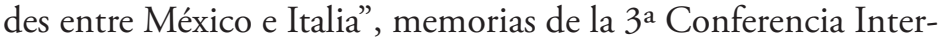
nacional de Psicología Comunitaria, Puebla, 3-5 de junio de 2010 (cartel arbitrada).

Kaneklin, Cesare (1993), Il gruppo in teoria e in pratica. Uno strumento per il lavoro psicologico, clinico e sociale, Raffaello Cortina, Milán.

Kanter, Rorsbeth Moss (1972), Commitment and community, Harvard University Press, Cambridge, Mass.

Kets-de Vries, Manfred F. R. (1989), Prisoners of Leadership, Wiley, Nueva York.

Kets-de Vries, Manfred F. R. (1994), "La mistica della leadership”, en Gian Piero Quaglino (ed.), Leadership. Nuovi profili di leader per nuovi scenari organizzativi, Raffaello Cortina, Milán, pp. 167-190.

King, Nigel (1998), "Template Analysis”, en Gillian Symon y Catherine Cassel (eds.), Qualitative methods and analysis in organizational research, Sage, Thousand Oaks, Cal.

Lewin, Kurt (1972), Teoria e sperimentazione in psicologia sociale, Il Mulino, Boloña.

Lombardi, Erika, Alessandro Messina y Olivia Polimanti (1999), Lavorare bene. Manuale sull'organizzazione e le forme di lavoro nel terzo settore, Lavoro, Roma.

Martín-Baró, Ignacio (1986), "Hacia una psicología de la liberación", Boletin de Psicologia (UCA), 22, pp. 219-231, http://www.uca.edu. sv/deptos/psicolog/hacia.htm, 12 de octubre de 2009.

Mochi-Alemán, Prudencio (2001), "Las organizaciones de la sociedad civil y las ciencias sociales. Su configuración en América Latina", Documento de Discusión sobre el Tercer Sector, núm. 16, El Colegio Mexiquense, A.C., Zinacantepec.

Montero, Maritza (1998), "Introduction: The Latin American approach to Community Psychology", Journal of Community Psychology, 26 (3), Towson, pp. 199-203. 
Montero, Maritza (2003), Teoría y práctica de la psicología comunitaria. La tensión entre comunidad y sociedad, Paidós, Buenos Aires.

Montero, Maritza y Cristopher Sonn (eds.) (2009), Psychology of Liberation. Theory and Applications, Springer, Nueva York.

Morgan, Gareth (2002), Images, Franco Angeli, Milán.

Pagliarani, Luigi (1973), "Apéndice didáctica" a la edición italiana de Isabel Menzies [1970], "I sistemi sociali come difesa dall'ansia. Studio sul servizio infermieristico di un ospedale", Psicoterapia e Scienze Umane, 1-2, Milán, pp. 56-64.

Pagliarani, Luigi (1985), Il coraggio di Venere. Anti-manuale di psico-socioanalisi della vita presente, Raffaello Cortina, Milán.

Pagliarani, Luigi (1996), "Intervista a Luigi Pagliarani” (por R. Camarlinghi), Animazione Sociale, 5, Turín, pp. 3-11.

Pauchant, Thierry (1991), "La leadership basata sul transfert", en Gian Piero Quaglino (ed.), Leadership. Nuovi profili di leader per nuovi scenari organizzativi, Raffaello Cortina, Milán, pp. 85-105.

Pearce, Jone L. (1993), Volontariato. Motivazioni e comportamenti nelle organizzazioni di lavoro volontario, Raffaello Cortina, Milán.

Perna, Tonino (1998), Fair Trade. La sfida etica al mercato mondiale, Bollati Boringhieri, Turín.

Piccardo, Claudia (1990), "Il paradigma politico e la direzione del personale", en Daniel Boldizzoni (ed.), Nuovi paradigmi per la direzione del personale, Isedi, Roma, pp. 79-102.

Piccardo, Claudia (1995), Empowerment. Strategie di sviluppo organizzativo centrate sulla persona, Raffaello Cortina, Milán.

Piccardo, Claudia (ed.) (1998), Insegnare e apprendere la leadership, Guerini, Milán.

Piccardo, Claudia (2002), "Riflessività, etnografia e approccio 'etnoclinico’ per l'analisi e l'intervento organizzativo", en Eraldo Cristiano 
Cassani y Gian Piero Quaglino (eds.), La comune organizzazione, Guerini, Milán, pp. 192-216.

Piccardo, Claudia y Angelo Benozzo (1996), Etnografia organizzativa, Raffaello Cortina, Milán.

Quaglino, Gian Piero (2004), La vita organizzativa, Raffaello Cortina, Milán.

Rosi, Marco (2003), "Decidere tra politica ed economia: il movimento del Commercio Equo e Solidale in Italia", en Paolo Ceri (ed.), $L a$ democrazia dei movimenti. Come decidono i Noglobal, Rubbettino, Soveria Mannelli, pp. 95-132.

Santana, Eugenia María (2005), "Algunas reflexiones en torno a la red mexicana de economía solidaria, Ecosol”, en Félix Cadena Barquín (ed.), De la economía popular a la economía de solidaridad. Itinerario de una búsqueda estratégica y metodológica para otro mundo posible, El Colegio de Tlaxcala, A.c., Tlaxcala, pp. 79-98.

Schwandt, Thomas (1994), "Constructivist, interpretivist approachs to human inquiry", en Norman Denzin e Yvonne Lincoln (eds.), Handbook of Qualitative Research, Sage, Thousand Oaks, Cal., pp. 118-137.

Strauss, Anselm Leonard y Juliette Corbin (1994), "Grounded theory methodology: an overview", en Norman Denzin e Yvonne Lincoln (eds.), Handbook of Qualitative Research, Sage, Thousand Oaks, Cal., pp. 273-285.

Ussher, Margarita (2006), "El objeto de la psicología desde el paradigma constructivista", Revista Electronica Internacional, 5, Union Latinoamericana de Entidades de Psicología <http://www.psicolatina. org/Cinco?comunitaria.html>, 15 de octubre de 2009.

Va-Maanen, John (1979), "La realtà dell'invenzione nell'etnografia delle organizzazioni”, en Pasquale Gagliardi (ed.), Le imprese come culture, Utet, Turín, pp. 33-50.

Vásquez-Rivera, Carlos (2004), "Refortalecimiento: un debate con el Empowerment", Interamerican Journal of Psychology, 38, Itajub, pp. 41-52. 
Walker, David, John Paul Jones III, Susan Roberts y Oliver Fröhlings (2007), "When participation meets empowerment: The wwF and the politics of invitation in the Chimalapas, Mexico", Annals of the Association of American Geographers, 97 (2), Washington, pp. 423-444.

Weber, Max (1995), Economia e società, Edizioni di Comunità, Milán.

Whyte, William Foote y Kathleen King Whyte (1988), Making Mondragón: The growth and dynamics of the Worker Cooperative Complex, Nyssilr, Nueva York.

Zimmermann, Marc (1999), "Empowerment e partecipazione della comunità. Un'analisi per il prossimo millennio", Animazione Sociale, 130, Turín, pp. 10-24.

Recibido: 12 de agosto de 2010. Reenviado: 12 de enero de 2011. Aceptado: 21 de enero de 2011.

Imke Hindrichs. Es doctora en psicodinámica de las relaciones y de los comportamientos de trabajo, organizativos e institucionales, por la Universidad de Turín. Actualmente labora como profesora investigadora de tiempo completo en la Facultad de Psicología de la Universidad Autónoma del Estado de Morelos (unem), Cuerpo Académico de Calidad de Vida. Sus líneas de investigación son: democracia organizativa y fortalecimiento en el tercer sector; investigación-acción y metodología cualitativa de la investigación social; psicología de la salud ocupacional, bienestar organizacional y riesgos psicosociales en el trabajo relacional. Entre sus últimas publicaciones destacan: "Il potere in gioco nell'empowerment, Un processo di emancipazione che coinvolge la sfera individuale, sociale e politica”, Animazione Sociale, 39 (234), Turín, pp. 62-69 (2009); en coautoría, "Empowerment individuale e organizzativo", en Piergiorgio Argentero, Claudio Giovanni Cortese y Claudia Piccardo (eds.), Manuale di Psicologia del Lavoro e delle Organizzazioni, vol. 3, RaffaelloCortina, Milán, pp. 209-229 (2010); Estrategias para la inversión en recursos humanos en las osc", ponencia presentada en el VI Congreso de la Asociación Latinoamericana de Sociología del Trabajo, 20-22 de abril de 2010, ciudad de México; "Wellbeing and Contrast of Discomfort in the Health Context: the Institution of Permanent Observatories in the Region Piedmont's Health Units", ponencia presentada en $9^{\text {th }}$ Conference of the 
European Academy of Occupational Health Psychology, 29-31 de marzo de 2010, Pontificial Urbania University, Roma.

Cristina Girardo. Es doctora en pedagogía por la Facultad de Ciencias de la Formación de la Universidad de Turín (1994) y doctora en estudios latinoamericanos por la Facultad de Ciencias Políticas y Sociales de la Universidad Nacional Autónoma de México (2003), donde recibió mención honorífica. Es investigadora de tiempo completo, adscrita/titular al Programa Interdisciplinario de Estudios sobre el Tercer Sector (PIETs) de El Colegio Mexiquense, A.C. Sus líneas de investigación son: estudios sobre sociedad civil: profesionalización y empleo en las organizaciones; responsabilidad social empresarial, democracia y participación. Estudios sobre desarrollo local: profesionalización de agentes de desarrollo local. Estudios sobre uso y apropiación de TIC: los centros comunitarios digitales y la concertación de actores para la ejecución de políticas públicas. Distinciones académicas: Promep, reconocimiento a perfil deseable y apoyo para profesor de tiempo completo, diciembre 2003-2010. Miembro del Sistema Nacional de Investigadores (SNI), nivel I, de enero de 2003 a diciembre de 2010. Es miembro del Comité Académico del Doctorado en Ciencias Sociales de El Colegio Mexiquense. Profesora de tiempo completo en la maestría en ciencias sociales de El Colegio Mexiquense. Profesora en la maestría de cooperación internacional para el desarrollo del Instituto Mora. Entre sus publicaciones recientes destacan: "La construcción, apropiación y difusión del conocimiento en la profesionalización de agentes para el desarrollo local", en Jorge Basave Kunhardt y Miguel Ángel Rivera Ríos (coords.), Globalización, conocimiento y desarrollo, t. II, unam, México, pp. 101-124 (2009); coord., El desarrollo local en México: aportes teóricos y empiricos para el debate, UNAM-UADY-Plan Estratégico de Mérida, Mérida (2008); "Profesionalización de los agentes de desarrollo local: la experiencia del Diplomado en Mérida, Yucatán, México, 20052006", en Cristina Girardo (coord.), El desarrollo local en México: aportes teóricos y empíricos para el debate, UNAM-UADY-Plan Estratégico de Mérida, Mérida, pp. 437-160 (2008); coord., La profesionalización de las OSC en México: actores y estrategias, El Colegio Mexiquense, Zinacantepec.

Daniela Converso. Es doctora magistral en ciencias políticas, por la Universidad de Turín. Es profesora de rol de segunda faja en la Facultad de Psicología, Universidad de Turín. Sus líneas de investigación son: psicología de la salud ocupacional y calidad de vida; riesgos psicosociales en el trabajo relacional; investigación-acción; fortalecimiento en el tercer sector; trabajo atípico en las cooperativas sociales. Publicaciones recientes: en coautoría, "Empowerment individuale e organizzativo", en Piergiorgio 
Argentero, Giovanni Claudio y Claudia Cortese (eds.), Manuale di Psicologia del Lavoro e delle Organizzazioni, vol. 3, Raffaello Cortina, Milán, pp. 209-229 (2010); "Estrategias para la inversión en recursos humanos en las OsC", ponencia presentada en el VI Congreso de la Asociación Latinoamericana de Sociología del Trabajo, 20-22 de abril de 2010, ciudad de México; "Wellbeing and Contrast of Discomfort in the Health Context: the Institution of Permanent Observatories in the Region Piedmont's Health Units", ponencia presentada en la $9^{\text {th }}$ Conference of the European Academy of Occupational Health Psychology, 29-31 de marzo de 2010, Pontificial Urbania University, Roma; "Il potere in gioco nell'empowerment, Un processo di emancipazione che coinvolge la sfera individuale, sociale e politica”, Animazione Sociale, 234 (39), Turín, pp. 62-69 (2009). 